\title{
Cathodic protection application possibilities in activity building of overhead lines: protection of armature tower foundations
}

\author{
A. Muharemovic, I. Turkovic \& S. Bisanovic \\ Faculty of Electrical Engineering, Sarajevo, Bosnia and Herzegovina
}

\begin{abstract}
This paper presents one practical method for the corrosion protection of armature tower foundations at overhead lines - the cathodic protection concept. The paper presents possible mechanisms of steel corrosion in concrete, as well as a discussion of the application of two dominant concepts: impressed current cathodic protection system and the system with galvanic anodes. The first system has the better performance and it is proposed as very efficient protection. In practice, for ensuring a significant saving in the supply of electrical energy from the distribution network, the application of solar energy system as support for impressed current cathodic protection system has been proposed. Also, real applications are been discussed with a presentation to satisfy need criterions and standards for each component of this system.

Keywords: cathodic protection, armature tower foundations, impressed current cathodic protection system, criterions and standards.
\end{abstract}

\section{Introduction}

With regards to the condition of usual building standards for making concrete (structure, additives), one can say that iron armature in concrete is corrosion inert. However, one can conclude that the corrosion of the armature in concrete is possible on certain conditions. The characteristic case is an iron armature in the footstep of tower foundations at overhead lines. Each footstep (four in total) has an iron anchor and an iron armature to make stronger concrete. On other hand, each footstep has its own ground (iron or copper). Contacts from different materials, as iron in concrete, iron in earth, copper in earth, results in the corrosion of the more negative metal. 
The first case is when the ground of tower and the armature of the footstep are made of same material, for example steel. Then the steady-state steel potential armature is less negative than steel potential in the earth. This results in the corrosion of the ground as the steel in earth act as the anode.

The second case is in the phase of building of overhead lines when the armature in footstep of the tower foundations is made of iron and ground of tower is made of copper. In this case, the iron armature in the concrete takes the role of the anode.

The next case that is independent of the ground type is the phenomenon of corrosion caused by the presence chloride in concrete. Chlorides in concrete can be the result of technology in concrete production. Chlorides are often present near to the armature in the upper layers - near the surface of the earth.

It is very important is to standardize a practice in application of cathodic protection of the armature in the footstep of tower foundations. A real practical solution is to use an impressed current cathodic protection system when needed great protection currents. For uniform protection current distribution, it is appropriate to use ribbon anodes typically installed into slots cut in the concrete [5-7].

A shortage of quality criteria for the evaluation successful completion of cathodic protection of armature tower foundations and relevant standards, are main reason for initiation theoretical and practices analysis in application this type of protection on vital objects, as are overhead lines.

\section{Possible mechanisms for steel corrosion in concrete}

When steel armature in concrete is analysed, with the assumption that the presence of ground is neglected, one can conclude that is the most important reason steel corrosion in concrete is due to the presence of chlorides. With presence of chlorides, steel is depolarized even in an electrolyte with high $\mathrm{pH}$ values.

The potential of iron in phase destruction of passive layer is moved towards more negative values. Parts of the armature near to the surface earth with presence chlorides are in metal connection with armature from deep layers of construction (foundation) where chlorides do not reach. For this reason, those corrosion microelements under the influence of a chloride armature will be anodes, with potential -0.5 (V) to a copper sulfate electrode (CSE) [3]. This part will be subject to corrosion process and the armature from deep layers is a cathode with potential -0.1 (V) to CSE and it will not corrode. Surface zone and deep zone can change places.

Chlorides can be included in concrete in many different ways. Pebble aggregate can contain chlorides, as can water, and a large amount of chlorides come in concrete are due to the use of calcium chloride as catalyst. External sources of chlorides include the sea atmosphere, with contact with seawater, etc. Corrosion element can be formed very often although are some parts of steel have good ventilation. With great rate cathode and anode surface and with good 
cathode ventilation, on anode area can appear intensive corrosion process. In those analyses it should be calculated with concrete resistivity $100 \div 2000(\Omega \mathrm{m})$ [4].

When steel armature in concrete is analysed, with presence of ground made as strip steel coated with zinc, then, without chlorides, one can conclude that is value of steel potential in concrete about $-0.2(\mathrm{~V})$ to $-0.3(\mathrm{~V})$ to CSE, while value of strip coated with zinc potential is more negative for at least $0.2(\mathrm{~V})$ or more [2]. In this case anode role is assigned to ground. Corrosion current depends of total resistance between ground and armature in concrete.

When steel armature in concrete is analysed, with presence of ground made as copper rope, then corrosion galvanic element copper/steel appears. Steady-state potential of copper in electrolyte is about $+0.3(\mathrm{~V})$ to CSE, while value of potential armature in concrete about -0.2 (V) to $-0.3(\mathrm{~V})$ to CSE [3]. The potential difference (operational voltage) between those electrodes is at least 0.5 (V), resulting to corrosion of steel in concrete as anode (more negative element).

In all three cases can be concluded that is, on one side, armature in concrete is connected with ground (over earth surface), and other side of electrical circuit is closed through earth. This connection, over earth surface, can be realized by appropriate resistance $\mathrm{R}$ (concrete resistance if direct contact do not exist), or by direct contact armature and anchor footstep of tower [1].

\section{Treatment of juncture copper/steel}

Independent to installing ground closeness in regard on footstep of tower foundations one can conclude that transition resistance of ground toward earth is small (this is one main characteristic of good ground). It increases current of corrosion element copper/steel armature in concrete. In this element role of anode is taking over by steel armature in concrete [3].

Here is need to point on electrical contact of clamp anchor tower and armature footstep of tower foundations. If no mutual direct contacts all elements of armature or armature with anchor exists, in parts of armature additional anode places are made (place where corrosion current leave one part of armature).

With aspect of corrosion, a combination of making ground by copper ropes for armature footstep of tower foundations is not good solution. A good variant for armature in concrete is coat with zinc strip, but this is not good solution for corrosion of ground. Those facts shows that optimal solution is application of cathodic protection system both ground and armature in concrete.

\section{Possible ways of corrosion protection}

For application of cathodic protection both ground and armature in concrete (meaning that electrical continuity of armature and her connection with ground exists) two methods can be used [1]:

- $\quad$ impressed current cathodic protection system and inert anode;

- $\quad$ system with galvanic anodes. 
A galvanic cathodic protection system consists of sacrificial anode(s) fixed to the underground metallic object and provides specified wiring for an inspection station installed near the surface of the ground. Galvanic systems have limited life spans during which the sacrificial anode will continue to degrade and protect the underground object. When the sacrificial anodes are no longer capable of protecting the object, they will lose their protection and begin to corrode. Galvanic anodes with very low operational voltage and concrete with very low electrical conductivity are unsuitable for this type of cathodic protection of steel in concrete and it has rare application.

The impressed current cathodic protection system usually provides electrodes of a much longer life span than a sacrificial anode. These systems include a rectifier that converts the alternating current power source to a direct current that is properly calibrated to provide the required protection. Since the power source is delivered to the electrode and is not generated by the degradation of the electrode, the power supply to the electrode may be recalibrated to provide additional power, when needed, as long as the electrodes are still functional. These systems are imperative in protection of armature tower foundations at overhead lines [2].

A big problem in application of cathodic protection on reinforced concrete constructions is high resistivity of concrete and small volume of electrolyte through protection current can flows to all parts of metal construction. Usually anodes are attached on concrete with layer cement mortar coating (Figure 1). Distance between anode and armature in concrete must be less then $1(\mathrm{~cm})$.

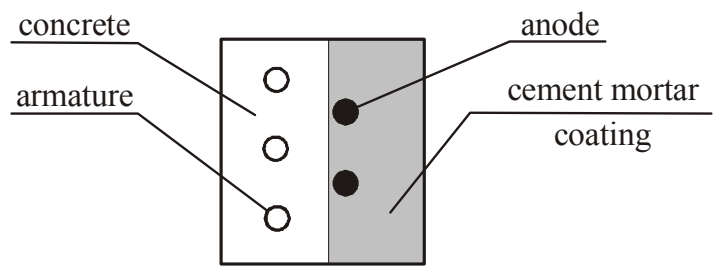

Figure 1: $\quad$ Concept anode and armature in concrete.

\section{Real application}

Often in practice anode system with titanium anodes (titan mesh) coated with mixed metal oxides (mixed metal coated titanium ribbon anodes) is applied. In Figure 2 principle scheme of anode system with mesh titanium anodes is illustrated (where do not take into consideration grounding system of tower).

Anodes are attached on surface concrete construction and covered with cement matter. If anode mesh is used, than uniform protection current distribution can be achieved, and mesh is easy to install on any surface. On this way installed titanium anodes can be calculated for life span more than 50 years.

In Figure 3 principle scheme of outputs from transformer rectifier for possible cathodic protection of armature tower foundations at overhead line and appropriate ground is illustrated. Positive and negative outputs must be enough 
for own supplying of each footstep of tower foundations. In electrical circuit must be installed regulation resistors in order to limitation of cathodic protection current. It is because that much less protection current of armature concrete then ground is needed. Ground of each tower foundation must have own secondary direct electrical circuit without regulation resistors [3].

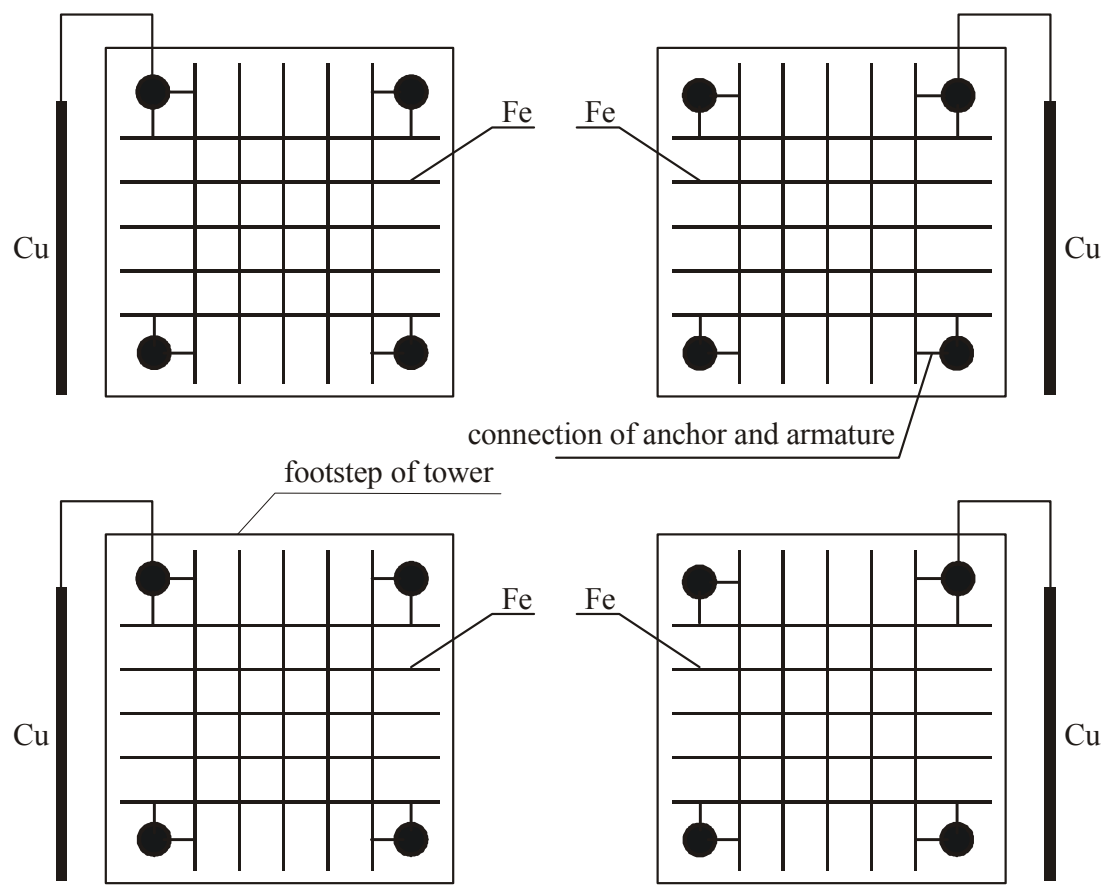

Figure 2: $\quad$ Principle scheme of anode system with mesh titanium anodes.

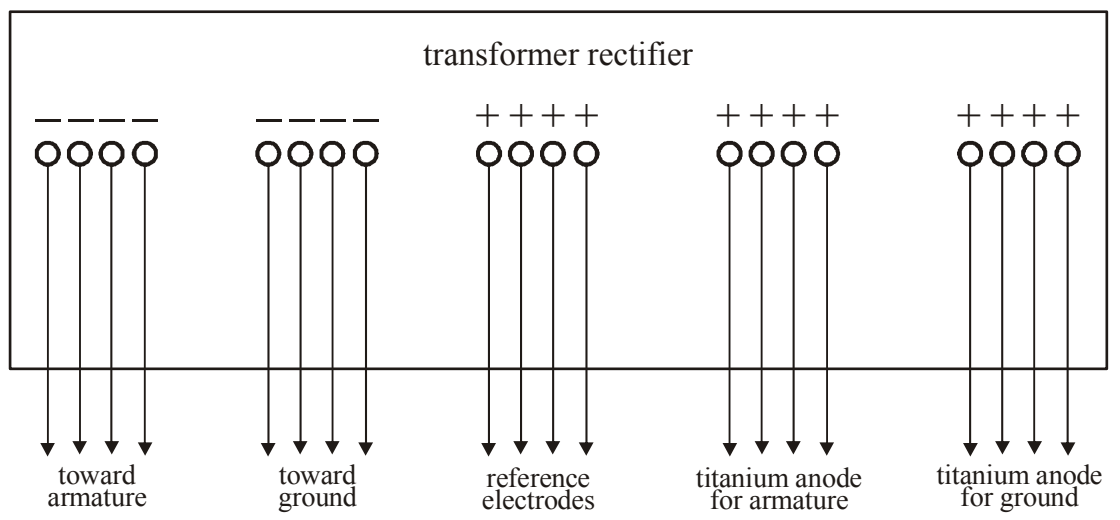

Figure 3: Principle scheme of outputs from transformer rectifier. 
In regard on very expensive way for ensuring supply from distribution network $240(\mathrm{~V}), 50(\mathrm{~Hz})$, one possibility is application of solar energy system. This system ensuring that battery has accumulated reserve energy minimum 48 (h).

Voltage characteristic of transformer rectifiers should be 48/60 (V) with minimal 8 outputs, total current 40 (A) and with operating current up to 15 (mA).

In box of transformer rectifier should be installed appropriate ammeters and voltmeters. Also, in this box should be brought outputs with permanent reference electrodes from each tower foundations separately [1].

In context of maintenance conditions, good solution is transformer rectifier with automatic regulation of output parameters - voltage toward maximum value of protection potential up to -2.0 (V) to CSE. In procedure of measuring protection potentials, for case that voltage droop component leave out is needed (in measured value), as well as that measuring of ON/OFF potentials can made, in transformer rectifier should be installed interrupter with appropriate time sets.

Anodes should be designed for life span up to 50 years. Ribbon titanium anodes should create anode system with appropriate plastic insulation at places of juncture. Length of anodes should be calculated according with dimensions of construction that is subject of protection. Protection current density of those anodes should be minimal $3\left(\mathrm{~A} / \mathrm{m}^{2}\right)$, where unit area by length minimum is 0.015 $\left(\mathrm{m}^{2} / \mathrm{m}\right)$ [3]. Anodes must be robust for montage in concrete.

Each footstep of tower foundations should be equipped with own anode system. Alternative is installation of anodes in ring form with two sides supplying.

For continuous measuring permanent reference electrodes are used (for each footstep of tower foundations - single electrodes). Their position is on most distant locations (geometrically) from anodes. In application $\mathrm{Ag} / \mathrm{AgCl}$ electrodes often are used.

Cable installation system with PVC/SVA/PVC cables and minimal cross section $10\left(\mathrm{~m}^{2}\right)$ should be used.

\section{Application of criterions and standards}

In calculation procedure, minimal protection current density for armature in concrete of $5\left(\mathrm{~A} / \mathrm{m}^{2}\right)$ and for ground minimal $20\left(\mathrm{~A} / \mathrm{m}^{2}\right)$ should be used. Criterion for potential is as follows: after depolarization (switch off cathodic protection system) minimal shift on negative side should be $10(\mathrm{mV})$ after 24 hours.

Cathodic protection system should be designed to satisfy following standards:

- NACE Standard RP 0177 Recommended Practice: Mitigation of Alternating Current and Lightning Effects on Metallic Structures and Corrosion Control Systems;

- NACE Standard RP 0187: Design Considerations for Corrosion Control of Reinforcing Steel in Concrete;

- $\quad$ NACE RP 0169-96: Control of External Corrosion on Underground or Submerged. Metallic Piping Systems; 
- $\quad$ BS 7361 PART 1 Cathodic Protection Part 1: Code of Practice for Land and Marine Applications.

\section{Conclusions}

Of all the various anti-corrosion systems used, cathodic protection is one of the most efficient for armature tower foundations protection. In application of this type of protection on vital object, as overhead lines are, in this paper proposed impressed current cathodic protection system which is safe and economical method. This paper has as goal to offer motivation on wide application of this type protection since decisions are often made to replace the tower rather than install a more economic solution as cathodic protection. Utilities that overcome this problem by establishing a comprehensive tower building program will reap considerable economic benefits [8].

\section{References}

[1] A. Muharemovic, Electric power system and environment, Sarajevo, 1996.

[2] J. Morgan, Cathodic protection, Second edition, Published by National Association of Corrosion Engineers, Houston, Texas, 1993.

[3] W. Baeckmann, W. Schwenk \& W. Prinz, Handbook of Cathodic Corrosion Protection, Gulf Publishing Company, Houston, Texas, 1997.

[4] A. Muharemovic, I. Turkovic, Aspects of cathodic protection solutions for city water wells Bacevo - Sarajevo, $9^{\text {th }}$ International expert meeting Power Engineering, Maribor, Slovenia, 1999.

[5] A. Muharemovic, I. Turkovic \& A. Kamenica, Analyse of the voltage component influence on the system measurement error of the stationary and protection potential, $5^{\text {th }}$ Libya Corrosion Conference, Benghazi, Libya, 2005.

[6] A. Muharemovic, I. Turkovic \& A. Kamenica, Distribution of the protection current and potential in system of cathodic protection with sacrificial anodes, $5^{\text {th }}$ Libya Corrosion Conference, Benghazi, Libya, 2005.

[7] A. Muharemovic, I. Turkovic, Procedure for calculation and measurement of parameters ground system as recommendations, Study, Faculty of Electrical Engineering, Sarajevo, Bosnia and Herzegovina, 2002.

[8] http://tdworld.com/mag/power_sweden_confronts_groundline/. 